\title{
Agricultural Products Crowd Logistics: A Literature Review and Research Agenda
}

\author{
Zhiwen Su*, Mingyu Zhang and Shuang Li \\ School of Economics and Management, Beijing Jiaotong University, Beijing, China \\ ${ }^{*}$ Corresponding author. Email: 19113070@bjtu.edu.cn
}

\begin{abstract}
As an innovative business model, agricultural products crowd logistics (APCL) is emerging rapidly. The focus of this paper is to carry out a literature review on APCL grounded in literature of crowd logistics (CL) and agricultural products logistics (APL), and then provides an agenda for future research. The research areas of CL focus on innovative business model, operational mechanism and value creation in urban area or cities, while researchers in the field of APL focus on logistics facility and equipment, operation mode, optimization of path planning, and, finally, logistics assessment. We propose the first conceptual definition of APCL. Potential topics, possible research questions, combined with relating research methods are provided for future research in order to deepen knowledge about APCL phenomenon.
\end{abstract}

Keywords: Crowd logistics, Agricultural products logistics, Literature review, Research agenda.

\section{INTRODUCTION}

APL set up a bridge between the production and consumption of agricultural products, which is vital to hundreds of millions of farmers. The development of Information and Communication technologies (ICT) has been accelerating mobile devices' penetration [1], such as mobile phones, laptop or tablet PCs, which then facilitates the current sharing economy boom. The idea of crowdsourcing provides new opportunities and innovative solutions for APL, so APCL, as an innovative business model, is emerging rapidly.

Related academic literature on CL has hitherto focused on three fields: innovative business model, operational mechanism and value creation in urban area or cities. APL has drawn much scholarly attention in various research areas: logistics facility and equipment, operation mode, optimization of path planning, and, finally, logistics assessment. APCL is a field worthy of extensive investigation; however, no existing study has drawn enough scholarly attention in this emerging research field in rural logistics context. In addition, no existing study has studied the relationship between logistics and rural revitalization. Based on our literature review, we summarises potential topics, possible research questions, and relating research methods.
The paper is organized as follows. First, we reviewed the literature of CL. Second, we reviewed the literature of APL. Third, a future research agenda is proposed in order to deepen knowledge about APCL. Finally, we come to a conclusion as well as the limitations of our work.

\section{CROWD LOGISTICS}

Most literature on $\mathrm{CL}$ to date has focused on innovative business model, operational mechanism and value creation.

\subsection{An Innovative Business Model}

In recent years, the popularity of e-commerce resulting in a large number of small-to-medium packages, coupled with higher consumer expectations for more convenient logistics and home delivery service, have compounded great challenges on logistics [2]. The rise of crowd practices is based on the assumption that financial, intellectual and physical resources possessed by individuals can be integrated and activated to fulfil traditional business activities by means of ICT platforms [3]. The idea of crowdsourcing provides new opportunities and innovative solutions for logistics, such as Uber and Didi. CL, as an innovative and sustainable business model, has the basic 
characteristics of crowdsourcing initiative [4], and can provides customers high-quality logistics service through big data-based logistics platforms which can provided informative support to coordinate demandsupply matching [5].

According to the form of transportation modes, scholars have focused on the business model of $\mathrm{CL}$ under the following two analytical frameworks. The first analysis framework composed of two subclasses explores CL where carriers drive their private vehicles to supply the demand of crowdshippers or consumers. The first subclass is that carriers are engaged in logistics distribution service along their scheduled trips and they are called occasional couriers. For example, Gdowska et al. (2018) studied how dynamic compensation strategies influence the willingness of in-store shoppers, as occasional couriers, to accept assigned parcels to other customers in a last-mile delivery system [6]. The second subclass is that carriers are engaged in logistics distribution service using their dedicated trips and they are called dedicated couriers. For example, Castillo et al.(2018) emphasized that CL carriers were independent contractors that use personally owned vehicles to supply transportation services for crowdshippers by means of dedicated trips[7]. For the reason that using private vehicles to accommodate the parcels may not reduce congestion and polluting emissions due to drivers making detours and extra stops, the second analysis framework focuses on public transport-based crowd logistics. For example, Gatta et al., (2019) investigated commuters using the metro of public transportation to get goods delivered in the $\mathrm{B} 2 \mathrm{C}$ e-commerce situation [8].

\subsection{Operational Mechanism}

In view of the above-mentioned business model, we argue that CL consists of multiple stakeholders who are crowdshippers, freight carriers, recipients, logistics platform providers, and, finally public transport operators. Crowdshippers and recipients are the demand side of crowdshipping services, and freight carriers supply side. The core characteristic of crowd logistics is the matching between both sides through on-line crowd logistics platforms. It is meaningful to investigate operational mechanism from the perspectives of logistics platform and both sides.

As for crowd logistics platforms, rigorous driver selection system, secure messaging system, demandsupply matching system, path planning system and secure online payment system are supposed to be integrated to platforms [9], of which informative support can coordinate logistics resource-demand match and influence logistics agility, thus improving logistics performance [5][10]. It is suggested that platform designers should analyse how a change of task load or task assignments impact drivers' behaviours, in that business model of CL may be intrusive to commuter workers who need to deviate from routine routes for carrying parcels[11]. Well-designed crowd logistics platforms can also promote collaborative consumption when integrated with item-sharing in sharing economy [12].

The increased attention in behaviour analysis of CL has led academic researchers in investigating crowdshipping acceptability from both demand side and supply side. From the demand side of logistics service, demographic characteristics, delivery distance, service quality, delivery timeliness and punctuality, personal privacy concerns, goods security and other aspects affect crowdshippers and recipients' acceptability of CL services [1] [13]. The supply side of logistics service concerns mainly on factors such as remuneration, detours, convenience, task duration, task difficulty and social influence [14]. There is one point which needs attention that different from traditional logistics and transportation with known capacities and availabilities, CL increases uncertainty of logistics service supply [7], which is manifested in the uncertain number of freight carriers and their transport capacities.

\subsection{Value Creation}

Researches exploring value creation of $\mathrm{CL}$ are gaining momentum. Above all, from the servicedominant logic perspective in business model of CL, the crowd undertaking certain logistics tasks are considered as co-creators of logistics value creation [3]. Next, CL not only allows crowdshippers (e.g. firms or stores) to avoid fixed costs and idle-time expenses due to freight carriers being employed by task rather than time, but also introduces new employment opportunities and thereby augments their income. Then, CL is able to alleviate traffic congestion in urban areas [15], for the reason that crowd logistics platforms can optimize vehicle resources. In addition, CL which can activate dispersed and dormant logistics resources is also believed to create certain environmental value, such as alleviating greenhouse gas and environmental pollution [8]. However, CL may have a rebound effect due to detour of routes, which will exacerbate environmental pollution and traffic congestion [16].

To the best of our knowledge, limited scientific research has been done on APCL in particular. There is a gap in academic knowledge concerning APL associated with CL. Based on our current study, we propose the first conceptual definition of APL:

Agricultural products crowd logistics is done through big data-based crowd logistics platform and mobile apps that connect freight carriers $180 \%$ are the farmer) and crowdshippers (farmers, wholesale market vendors, commercial enterprises, etc.), in order to solve 
the problem of resource fragmentation and low efficiency of agricultural products logistics.

\section{AGRICULTURAL PRODUCTS LOGISTICS}

APL has drawn much scholarly attention in various research areas: logistics facility and equipment, operation mode, optimization of path planning, and, finally, logistics assessment. Table 1 demonstrates research area and core focus of the articles we have reviewed.

\subsection{Logistics Facility and Equipment}

Logistics facility and equipment (e.g., logistics vehicle, freight village, storage materials) is the foundation of the development of APL. Generally, driving road conditions in rural areas can be complicated and irregular, which bring challenges to vehicle stability control. Zhou and Zhou (2020) studied data-driven driving state control method to realize intelligent driving in such situations [17]. Agricultural product logistics centres or freight villages serve as a bridge which can break logistics bottlenecks hindering the linking between upstream farmers and downstream agricultural product vendors [18]. Their locations have a great influence on exchanges efficiency of both sides. Huang et al. (2019) applied the method of multiattribute decision making with double-reference points to the location of APL center [19]. Zhou et al. (2016) proposed a layout planning innovation method for urban green logistics centres from the perspective of construction innovation [20]. As for storage materials, phase change coolants were proved to be an effective pathway to maintain the quality of agricultural products [21].

Table 1. Research area and core focus of reviewed articles

\begin{tabular}{|c|c|c|}
\hline $\begin{array}{l}\text { Research } \\
\text { area }\end{array}$ & Core focus & References \\
\hline \multirow{5}{*}{$\begin{array}{l}\text { Logistics } \\
\text { Facilities and } \\
\text { Equipment }\end{array}$} & Driving state control for agricultural logistics vehicle & Zhou and Zhou (2020) \\
\hline & Location of APL center & Huang et al. (2019) \\
\hline & Application research of nano-storage materials & Bai et al. (2019) \\
\hline & Freight villages & Wu and Haasis (2018) \\
\hline & Urban green logistics centers for agricultural products & Zhou et al. (2016) \\
\hline \multirow{4}{*}{$\begin{array}{l}\text { Operation } \\
\text { Mode }\end{array}$} & $\begin{array}{l}\text { The cooperation among commercial express enterprises, local } \\
\text { logistics provider and logistics providers concerned with integrated } \\
\text { delivery and installation }\end{array}$ & Yang et al. (2020) \\
\hline & $\begin{array}{l}\text { The cooperation among agricultural production and processing } \\
\text { enterprises, third-party logistics enterprises and financial institutions }\end{array}$ & Yang (2019) \\
\hline & $\begin{array}{l}\text { A three-level distribution system with a vendor, a third- party } \\
\text { logistics company and multiple geographically dispersed retailers }\end{array}$ & Zhang et al. (2017) \\
\hline & A cross border electricity supplier logistics system & $\mathrm{Hu}(2017)$ \\
\hline \multirow{5}{*}{$\begin{array}{l}\text { Optimization } \\
\text { of Path } \\
\text { Planning }\end{array}$} & The sweep-adaptive genetic algorithm & Zhu et al. (2020) \\
\hline & The ant colony algorithm & $\begin{array}{l}\text { Feng (2020); Liu et al. } \\
(2019)\end{array}$ \\
\hline & The improved ant colony algorithm & $\mathrm{Li}(2017)$ \\
\hline & The heuristic swarm intelligent optimization algorithm & Chen et al. (2019) \\
\hline & The hybrid time window algorithm & Jia (2017) \\
\hline \multirow{4}{*}{$\begin{array}{l}\text { Logistics } \\
\text { Assessment }\end{array}$} & Risk assessment & $\begin{array}{l}\text { Zhang et al. (2020); Zhang et } \\
\text { al. (2017) }\end{array}$ \\
\hline & Evaluation of green logistics system & Ni et al. (2019) \\
\hline & Evaluation of regional logistics competitiveness & Sheng (2014) \\
\hline & Technical efficiency measurement & Zhang et al. (2016) \\
\hline
\end{tabular}




\subsection{Operation Mode}

There are four operation modes considering cooperation among multiple logistics stakeholders to reduce the logistics cost and promote the logistics efficiency in rural areas. The first operation mode focus on the cooperation among commercial express enterprises, local logistics provider and logistics providers concerned with integrated delivery and installation [22]. The second operation mode is about the cooperation among agricultural production and processing enterprises, third-party logistics enterprises and financial institutions, by which three parties can realize win-win outcomes [23]. A three-level distribution system focusing on the performance of the whole supply chain is the third one, in which a vendor, a third-party logistics company and multiple geographically dispersed retailers cooperate with each other mainly from the vertical value chain perspective [24]. Lastly, $\mathrm{Hu}$ (2017) studied on integrated optimization model of intelligent logistics network of agricultural product and cross border electricity supplier in free trade zone [25].

\subsection{Optimization of Path Planning}

Many studies take optimization of algorithms as the main target to carry on path planning or design transportation routes. To sum up, five algorithms were discussed and applied into APL practices: the sweepadaptive genetic algorithm [26], the ant colony algorithm [27, 28], the improved ant colony algorithm [29], the heuristic swarm intelligent optimization algorithm [30] and the hybrid time window algorithm [31]. The latest researches have focused on the maturity of agricultural products which have a quality decay nature and shelf-life in optimization of distribution planning for the reason that the degree of maturity is considered as a critical factor determining the delivery time, especially for respiratory climacteric fruits. For example, Liu et al. (2019) argued that the ant colony algorithm considering the maturity of agricultural products can realize the validity to improve the distribution efficiency [27], while Zhu et al. (2020) studied integrated tomato picking and distribution scheduling using the sweep-adaptive genetic algorithm [26].

\subsection{Logistics Assessment}

Some researchers have focused on the logistics assessment aspects, which have much impact in the operation of APL. First, the way how to predict and control risk in order to enhance the efficiency and profits has become an urgent problem to be solved.
Zhang et al. (2017) developed a quantitative risk assessment method to assess the condition of the fresh agricultural products cold chain process [32]. Second, in order to solve the environmental issue caused by logistics of agricultural products, $\mathrm{Ni}$ et al. (2019) established a scientific and reasonable agricultural products green logistics evaluation system [33]. What's more, Zhang et al. (2016) and Sheng (2014) studied evaluation of regional logistics competitiveness and technical efficiency measurement respectively using the panel data of 31 provinces $[34,35]$.

APCL is a field worthy of extensive investigation; however, no existing study has drawn enough scholarly attention in this emerging research field in the rural logistics context. In addition, no existing study has studied the relationship between logistics and rural revitalization. To fill these gaps, we propose future research agenda which need to be further investigated in the next section.

\section{RESEARCH AGENDA}

We provide future research directions in order to deepen knowledge about the APCL initiative. Table 2 summarizes potential topics, possible research questions, and relating research methods.

While we propose the conceptual definition of APCL after reviewing CL literatures, the operation mode of APCL is still to be studied, using case studies or grounded theory method. No existing articles focus on optimization of path planning in the CL context, so optimization or experiment, together with system dynamics simulation are applied to develop optimal path planning for a combined occasional couriers and dedicated couriers. Then we should have a good knowledge concerning strengths and weaknesses of APCL compared to other logistics models in the supply chain.

Understanding how APCL promote rural revitalization using grounded theory or structural equation modelling method is significant. Specifically, delphi surveys, structural equation modelling approach would serve in understanding the function mechanisms between APCL and income of farmers, the employment of farmers or rural financial development.

In addition, understanding influencing factor of motivations of drivers may help develop more effective human resource management policies. Finally, drivers become de facto frontline employees of the crowd logistics platforms whose behaviours will affect brand building of crowd logistics platform, so it is crucial to study their effect on brand image. 
Table 2. Future research

\begin{tabular}{|l|l|l|}
\hline \multicolumn{1}{|c|}{ Potential Topic } & \multicolumn{1}{|c|}{ Possible Research Question (s) } & \multicolumn{1}{c|}{ Possible method(s) } \\
\hline Research on Operation Mode & $\begin{array}{l}\text { How does operation mode of APCL work? What are } \\
\text { applications of this business model? }\end{array}$ & Case Studies, Grounded Theory \\
\hline Optimization of Path Planning & $\begin{array}{l}\text { How can crowd logistics platforms determine the optimal } \\
\text { path planning for a combined occasional couriers and } \\
\text { dedicated couriers? }\end{array}$ & $\begin{array}{l}\text { Optimization, Experiment, } \\
\text { System Dynamics Simulation }\end{array}$ \\
\hline $\begin{array}{l}\text { APCL and Supply Chain } \\
\text { Management }\end{array}$ & $\begin{array}{l}\text { How does APCL compare to other logistics models in the } \\
\text { supply chain? }\end{array}$ & $\begin{array}{l}\text { Case Studies, the Multi-Actor } \\
\text { Multi-Criteria Analysis }\end{array}$ \\
\hline $\begin{array}{l}\text { Relationship Between APCL } \\
\text { and Rural Revitalization }\end{array}$ & How does APCL promote rural revitalization? & $\begin{array}{l}\text { Grounded Theory, Structural } \\
\text { Equation Modeling }\end{array}$ \\
\hline $\begin{array}{l}\text { Impact on the Income of } \\
\text { Farmers }\end{array}$ & $\begin{array}{l}\text { What is the function mechanism between APCL and income } \\
\text { of farmers? }\end{array}$ & $\begin{array}{l}\text { Delphi Surveys, Structural } \\
\text { Equation Modeling }\end{array}$ \\
\hline $\begin{array}{l}\text { Impact on the Employment of } \\
\text { Farmers }\end{array}$ & $\begin{array}{l}\text { What is the function mechanism between APCL and the } \\
\text { employment of farmers? }\end{array}$ & $\begin{array}{l}\text { Delphi Surveys, Structural } \\
\text { Equation Modeling }\end{array}$ \\
\hline $\begin{array}{l}\text { Impact on Rural Financial } \\
\text { Development }\end{array}$ & $\begin{array}{l}\text { What is the function mechanism between APCL and rural } \\
\text { financial development? }\end{array}$ & $\begin{array}{l}\text { Delphi Surveys, Structural } \\
\text { Equation Modeling }\end{array}$ \\
\hline Motivations of Drivers & $\begin{array}{l}\text { How do drivers differ in terms of motivation? Why are } \\
\text { some drivers more responsive than others? }\end{array}$ & Survey, Case Studies \\
\hline Brand Management & $\begin{array}{l}\text { How do crowdshippers, recipients perceive the level of } \\
\text { logistics service quality from a driver of APCL, compared to } \\
\text { other modes of delivery? }\end{array}$ & $\begin{array}{l}\text { Grounded Theory, Experiments, } \\
\text { Delphi Surveys }\end{array}$ \\
\hline
\end{tabular}

\section{CONCLUSION}

The purpose of this study is to conduct a literature review on APCL grounded in literature of CL and APL. Related academic literature has hitherto focused on three fields of CL practices: innovative business model, operational mechanism and value creation, by which we get a deeper understanding on crowd logistics. Literature generally limits CL concept to in urban area or cities. Prior studies in the literature concerned with APL have considered logistics facility and equipment, operation mode, optimization of path planning and logistics assessment extensively. Finally, we provide potential topics, possible research questions, empirical and qualitative research methods about APCL in order to deepen our knowledge about this phenomenon.

However, this literature review was limited to papers published in English language and peer-reviewed journals. Other sources, such as papers indexed in Chinese Social Sciences Citation Index (CSSCI) or conference proceedings may be included in future review.

\section{AUTHORS' CONTRIBUTIONS}

All authors made substantial contributions to the paper. Zhang proposed the research idea, provided research support and revised it critically for significant improvement. Su drafted and edited the original manuscript. $\mathrm{Li}$ made constructive comments and suggestions.

\section{ACKNOWLEDGMENTS}

This work was supported by the Major Program of The National Social Science Fund of China under Grant No.15ZDA022.

\section{REFERENCES}

[1] Punel, A., A. Ermagun, and A. Stathopoulos, Studying determinants of crowd-shipping use. Travel Behaviour and Society, 2018. 12: pp. 30-40. DOI:https://doi.org/ 10.1016/j.tbs.2018.03.005.

[2] Ermagun, A., A. Shamshiripour, and A. Stathopoulos, Performance analysis of crowdshipping in urban and suburban areas. Transportation, 2020. 47(4): pp. 1955-1985. DOI:https://doi.org/ 10.1007/s11116-019-10033-7.

[3] Carbone, V., A. Rouquet, and C. Roussat, The Rise of Crowd Logistics: A New Way to Co-Create Logistics Value. Journal of Business Logistics, 2017. 38(4): pp. 238-252. DOI:https://doi.org/ $10.1111 / \mathrm{jbl} .12164$

[4] Estelles-Arolas, E. and F. Gonzalez-Ladron-deGuevara, Towards an integrated crowdsourcing definition. Journal of Information Science, 2012. 38(2): pp. 189-200. DOI:https://doi.org/ $10.1177 / 0165551512437638$.

[5] Zhang, M., et al., Crowd Logistics Platform's Informative Support to Logistics Performance: Scale Development and Empirical Examination. Sustainability, 2019. 11(2). DOI:https://doi.org/ 10.3390/su11020451.

[6] D, K.G.A., A.V.B. D, and J.P.P.C. D, Stochastic last-mile delivery with crowdshipping. Transportation Research Procedia, 2018. 30: pp. 90-100.

[7] Castillo, V.E., et al., Crowdsourcing Last Mile Delivery: Strategic Implications and Future Research Directions. Journal of Business Logistics, 
2018. 39(1): pp. 7-25. DOI:https://doi.org/ $10.1111 / \mathrm{jbl} .12173$.

[8] Gatta, V., et al., Public Transport-Based Crowdshipping for Sustainable City Logistics: Assessing Economic and Environmental Impacts. Sustainability, 2019. 11(1). DOI:https://doi.org/ $10.3390 /$ su11010145

[9] Rai, H.B., et al., Crowd logistics: an opportunity for more sustainable urban freight transport? European Transport Research Review, 2017. 9(3). DOI:https://doi.org/ 10.1007/s12544-017-0256-6.

[10] Li, S., et al., How do crowd logistics platforms create value? An exploratory case study from China. International Journal of Logistics-Research and Applications, 2019. 22(5): pp. 501-518. DOI:https://doi.org/ 10.1080/13675567.2019.1628929.

[11] Lin, X., Y. Nishiki, and L.A. Tavasszy, Performance and Intrusiveness of Crowdshipping Systems: An Experiment with Commuting Cyclists in The Netherlands. Sustainability, 2020. 12(17). DOI:https://doi.org/ 10.3390/su12177208.

[12] Behrend, M. and F. Meisel, The integration of item-sharing and crowdshipping: Can collaborative consumption be pushed by delivering through the crowd? Transportation Research Part BMethodological, 2018. 111: pp. 227-243. DOI:https://doi.org/ 10.1016/j.trb.2018.02.017.

[13] Marcucci, E., et al., Connected shared mobility for passengers and freight: investigating the potential of crowdshipping in urban areas. 2017 5th Ieee International Conference on Models and Technologies for Intelligent Transportation Systems. 2017. 839-843.

[14] Gatta, V., et al., Sustainable urban freight transport adopting public transport-based crowdshipping for B2C deliveries. European Transport Research Review, 2019. 11(1). DOI:https://doi.org/ 10.1186/s12544-019-0352-X.

[15] Chen, W., M. Mes, and M. Schutten, Multi-hop driver-parcel matching problem with time windows. Flexible Services and Manufacturing Journal, 2018. 30(3): pp. 517-553. DOI:https://doi.org/ 10.1007/s10696-016-9273-3.

[16] Simoni, M.D., et al., Potential last-mile impacts of crowdshipping services: a simulation-based evaluation. Transportation, 2020. 47(4): pp. 19331954. DOI:https://doi.org/ 10.1007/s11116-01910028-4.

[17] Zhou, X.S. and J. Zhou, Data-Driven Driving State Control for Unmanned Agricultural Logistics
Vehicle. Ieee Access, 2020. 8: pp. 65530-65543. DOI:https://doi.org/ 10.1109/access.2020.2983424.

[18] Wu, J.N. and H.D. Haasis, The freight village as a pathway to sustainable agricultural products logistics in China. Journal of Cleaner Production, 2018. 196: pp. 1227-1238. DOI:https://doi.org/ 10.1016/j.jclepro.2018.06.077.

[19] Huang, X.R., R.H. Xie, and L.J. Huang, Real-time emergency management mode of cold chain logistics for agricultural products under the background of "Internet plus ". Journal of Intelligent \& Fuzzy Systems, 2020. 38(6): pp. 7461-7473. DOI:https://doi.org/ 10.3233/jifs179819.

[20] Zhou, L.Y., et al., Construction innovation of urban green logistics centers for agricultural products. Open House International, 2016. 41(3): pp. 26-31.

[21] Bai, B., K. Zhao, and X.Z. Li, Application research of nano-storage materials in cold chain logistics of e-commerce fresh agricultural products. Results in Physics, 2019. 13: pp. 8. DOI:https://doi.org/ 10.1016/j.rinp.2019.01.083.

[22] Yang, F., Y. Dai, and Z.J. Ma, A cooperative rich vehicle routing problem in the last-mile logistics industry in rural areas. Transportation Research Part E-Logistics and Transportation Review, 2020. 141: pp. 21. DOI:https://doi.org/ 10.1016/j.tre.2020.102024.

[23] Yang, B., Machine learning-based evolution model and the simulation of a profit model of agricultural products logistics financing. Neural Computing \& Applications, 2019. 31(9): pp. 4733-4759. DOI:https://doi.org/ 10.1007/s00521-019-04072-5.

[24] Zhang, S.S., K. Guo, and Y. Sun, Study on integrated optimization model of inventory and routing problem and its application in China's online agricultural products logistics. Custos E Agronegocio on Line, 2017. 13(2): pp. 73-87.

[25] Hu, Y.B., The optimization model of cross border electricity supplier and intelligent logistics network of agricultural product in free trade zone. Agro Food Industry Hi-Tech, 2017. 28(3): pp. 970-975.

[26] Zhu, A.Q., et al., Integrated Tomato Picking and Distribution Scheduling Based on Maturity. Sustainability, 2020. 12(19): pp. 17. DOI:https://doi.org/ 10.3390/su12197934.

[27] Liu, L., H. Wang, and S.H. Xing, Optimization of distribution planning for agricultural products in logistics based on degree of maturity. Computers and Electronics in Agriculture, 2019. 160: pp. 1-7. 
DOI:https://doi.org/

10.1016/j.compag.2019.02.030.

[28] Feng, Z.T., Constructing rural e-commerce logistics model based on ant colony algorithm and artificial intelligence method. Soft Computing, 2020. 24(11): pp. 7937-7946. DOI:https://doi.org/ 10.1007/s00500-019-04046-8.

[29] Li, P.J., Logistics transportation route for agricultural products based on an improved ant colony algorithm. Agro Food Industry Hi-Tech, 2017. 28(1): pp. 1876-1880.

[30] Chen, L.M., M.L. Ma, and L.X. Sun, Heuristic swarm intelligent optimization algorithm for path planning of agricultural product logistics distribution. Journal of Intelligent \& Fuzzy Systems, 2019. 37(4): pp. 4697-4703. DOI:https://doi.org/ 10.3233/jifs-179304.

[31] Jia, X.Y., Analysis and Research on B2C Model of Agricultural Product Logistics Distribution under Electronic Commerce Mode. Agro Food Industry Hi-Tech, 2017. 28(1): pp. 1122-1126.
[32] Zhang, H., B. Qiu, and K.M. Zhang, A new risk assessment model for agricultural products cold chain logistics. Industrial Management \& Data Systems, 2017. 117(9): pp. 1800-1816. DOI:https://doi.org/ 10.1108/imds-03-2016-0098.

[33] Ni, S.Y., et al., An evaluation method for green logistics system design of agricultural products: A case study in Shandong province, China. Advances in Mechanical Engineering, 2019. 11(1): pp. 9. DOI:https://doi.org/ 10.1177/1687814018816878.

[34] Zhang, Z.J., et al., Technical efficiency measurement and upgrading strategy for the agricultural product logistics industry in China. Agro Food Industry Hi-Tech, 2016. 27(6): pp. 106112.

[35] Sheng, Z., The evaluation of regional logistics competitiveness of agricultural products in china and spatial analysis on the differences. Pakistan Journal of Statistics, 2014. 30(5): pp. 683-702. 